\title{
Using Real Field Construction as a Platform for Teaching Introductory Geotechnical Engineering
}

\author{
Charles E. Pierce \\ University of South Carolina
}

\begin{abstract}
This paper describes a unique approach for teaching geotechnical engineering to civil engineering undergraduates. While many undergraduate students recognize the discipline of structural engineering early in the curriculum, most students are not aware of geotechnical engineering until their first course on the subject, which is usually taken in the junior year. Thus most students do not recognize the strong link between the disciplines of geotechnical and structural engineering. To help students understand this connection and more fully comprehend fundamental geotechnical engineering concepts, an approach of using a real field construction project to support the teaching of this introductory course is being developed. For this approach to work most effectively, the entire course must be centered on a selected project. The University of South Carolina and metropolitan Columbia are experiencing a building boom, making this an ideal opportunity for this approach. One of the most recognized projects on campus is the construction of a new arena for basketball and ice hockey. The high visibility of this project generates greater student interest about learning concepts necessary to "build" the arena. This method has not yet been utilized in a course but is being developed for the next offering of Introductory Geotechnical Engineering. The paper provides a description of the new course platform and summarizes survey results of former students on the proposed method.
\end{abstract}

\section{Introduction}

Teaching the fundamental concepts of geotechnical engineering using traditional methods of lecture-based instruction and hands-on laboratory testing can be effective, based on the author's experience. However, using a real, on-going field construction project as a platform for teaching these concepts can enhance these traditional methods. It is important to recognize that this teaching strategy does not intend to create an entirely project-based learning environment ${ }^{1}$; in other words, students will not, for example, design a foundation for a new structure by investigating the properties of the soil strata. Undergraduate students experience project-based learning in Senior Engineering Design where each group is required to design structural foundations. Rather than repeat this experience, the proposed concept uses a real, on-going construction project as a central theme for teaching concepts in geotechnical engineering. The resulting teaching strategy essentially becomes enhanced activity-based instruction ${ }^{1}$ that draws from some project-based learning objectives. 


\section{Teaching Platform for Course}

There are three major course topics for Introductory Geotechnical Engineering: 1) Site Exploration, 2) Soil Classification and 3) Soil Properties. Instead of simply providing the major study topics to the students, the author believes that the students should determine these topics for themselves. To do so, there are three important questions that students need to raise about the subsurface when constructing in or above ground. The first question is "What's there?" and the second question is "What do we need to know about it?" These two questions define the topics of soil classification and soil properties, and it is important that students recognize the importance of asking both questions. To direct this thought process, the author intends to start the first class period with a simple drawing like the one shown in Figure 1.

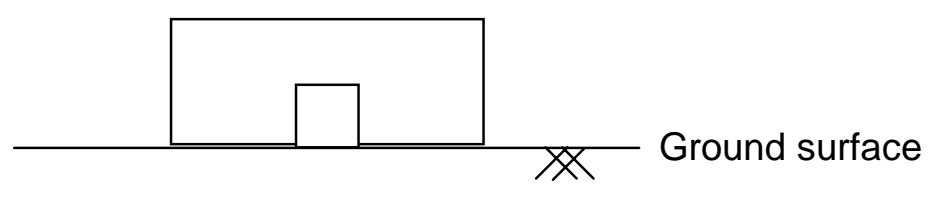

(blank space) Subsurface

Figure 1. Simple Sketch of Structure Above Unknown Subsurface

To emphasize the importance of the unknown subsurface, the blank space beneath the structure should be extended as far as possible. At this point, students should be asked to discuss the unknown subsurface in an effort to direct them to the two main questions. This exercise can be conducted individually, in small groups, or as a whole class. Once students have reached an agreement on the two important questions, one final question remains: "How do we find out what's there and how do we acquire the information we need to know about it?" This final question leads directly into the topic of site exploration and the beginning of the course.

The introductory lecture for this, or any course, is critical and needs to capture the students' full attention immediately. In past course offerings, the author started with a general introduction to the field of geotechnical engineering, which has not been particularly effective. With this concept of real field construction, the entire course will revolve around a single construction project. Using the sketch in Figure 1, students will begin thinking immediately about how the subsurface impacts the construction of each and every building.

The second class period is dedicated to the description of the selected construction project and is more effective if accompanied by an introduction from the project engineers. One of the goals of this teaching strategy is to also initiate interaction between the students and local consulting engineers. Informal discussions with students and local engineers suggest that this interaction is 
highly desired by both parties. After only two class periods, the students are now prepared to raise the three main questions about the subsurface for the selected construction project. It is important that a nearby project that is currently under construction is selected so that students can visit the site and see the project during different stages of construction. It is recognized that the construction timeline will not necessarily coincide with the course timeline, but efforts will be made to choose projects carefully to maximize interaction.

Students will visit the field site periodically to complement specific concepts and laboratory experiments. For example, an initial field visit will allow students to review the site soil report and retrieve soil samples to be used in the laboratory for further testing. If possible, students will witness site exploration activity such as Shelby tube sampling, standard penetration testing or cone penetration testing. If not, a collection of video images of this activity will be coordinated with the participating consultant. Using real field samples, students will classify the soil and perform laboratory tests on Proctor compaction, hydraulic conductivity, consolidation and direct shear, among other possible tests. When possible, these individual laboratory tests will be complemented with field visits to witness field compaction, field measurements of hydraulic conductivity, and accelerated field consolidation. The findings of each laboratory and field test will always be discussed in context of its importance to the construction project.

Some advantages of this approach include: 1) direct incorporation of the laboratory course into the core course; 2) multiple field trips to a single construction site at different stages; 3 ) provision of "field visualization" of specific geotechnical concepts; 4) contact with the local engineering community; and 5) an understanding of the link between geotechnical and structural engineering under the umbrella of construction. Some of the disadvantages are that it requires timing that meets the course schedule and coordination with a willing participant from the engineering community.

\section{Student Survey}

To assess the potential impact of this new teaching strategy, the author conducted an e-mail survey of former students from the past two classes. A total of 22 out of 53 students responded, yielding a response rate of $42 \%$. The majority of responses were received from the most recent class conducted during the Spring 2000 semester. The survey summary provided to the students reads as follows:

"I am planning to moderately change how ECIV 330 is taught in an effort to improve students' learning of soil mechanics. I believe that students will better understand the fundamental concepts of soil mechanics if they can directly and immediately relate the concepts to real field construction. As such, I intend to center the teaching of these concepts around a highly visible field project, like the building of the new "Coliseum" on campus. All concepts (such as compaction, consolidation and shear strength) will be presented specifically as it relates to the project site conditions. As part of this approach, the class would interact with actual project personnel on site, reviewing site soil conditions and collecting real field samples for lab testing.

Proceedings of the 2001 American Society for Engineering Education Annual Conference \& Exposition Copyright (C) 2001, American Society for Engineering Education 
This approach does not intend to duplicate efforts of Senior Design; rather, it simply takes a current construction project and uses it as a way to teach the fundamental concepts more clearly."

Students were asked to respond to five questions. The first two questions address learning in the classroom during the lecture period, and the remaining three questions address issues with the laboratory course. The questions are listed as follows:

1. This new approach would enhance my individual ability to better understand fundamental soil mechanics concepts.

2. This new approach would enhance others' ability to better understand fundamental soil mechanics concepts.

3. This new approach would help me link the fundamental concepts taught in the classroom to the tests performed in lab.

4. Instead of multiple lab reports, this new approach would require only two soils' reports (an interim report and a final report). The reduction in the number of reports required would be beneficial to the class.

5. This new approach would require multiple field visits to the project site during the semester (during the laboratory period). These field visits would be beneficial to the class.

Students answered each question by selecting one of the listed responses: Strongly Agree, Agree, Neutral, Disagree or Strongly Disagree. Each response was assigned a numerical value from 0 to 4, with 0 representing Strongly Disagree and 4 representing the highest rating of Strongly Agree. With the exception of Question 4, all survey questions received a total rating between Agree and Strongly Agree, as shown in Table 1. The distribution of responses for all five questions is shown in Figures 2 and 3. Only Question 4 received responses of Neutral and Disagree, and no question received any response of Strongly Disagree.

Table 1. Results of Student Survey

\begin{tabular}{|c|c|c|c|}
\hline \multicolumn{3}{|c|}{ Question } & \multicolumn{2}{c|}{ Total Rating } \\
\hline 1 & Enhance individual learning? & Agree to Strongly Agree & 3.45 \\
\hline 2 & Enhance classmates' learning? & Agree to Strongly Agree & 3.41 \\
\hline 3 & Enhance laboratory learning? & Agree to Strongly Agree & 3.59 \\
\hline 4 & Reduce laboratory reports? & Neutral & 2.09 \\
\hline 5 & Increase field trips? & Agree to Strongly Agree & 3.41 \\
\hline
\end{tabular}

Proceedings of the 2001 American Society for Engineering Education Annual Conference \& Exposition Copyright (C) 2001, American Society for Engineering Education 


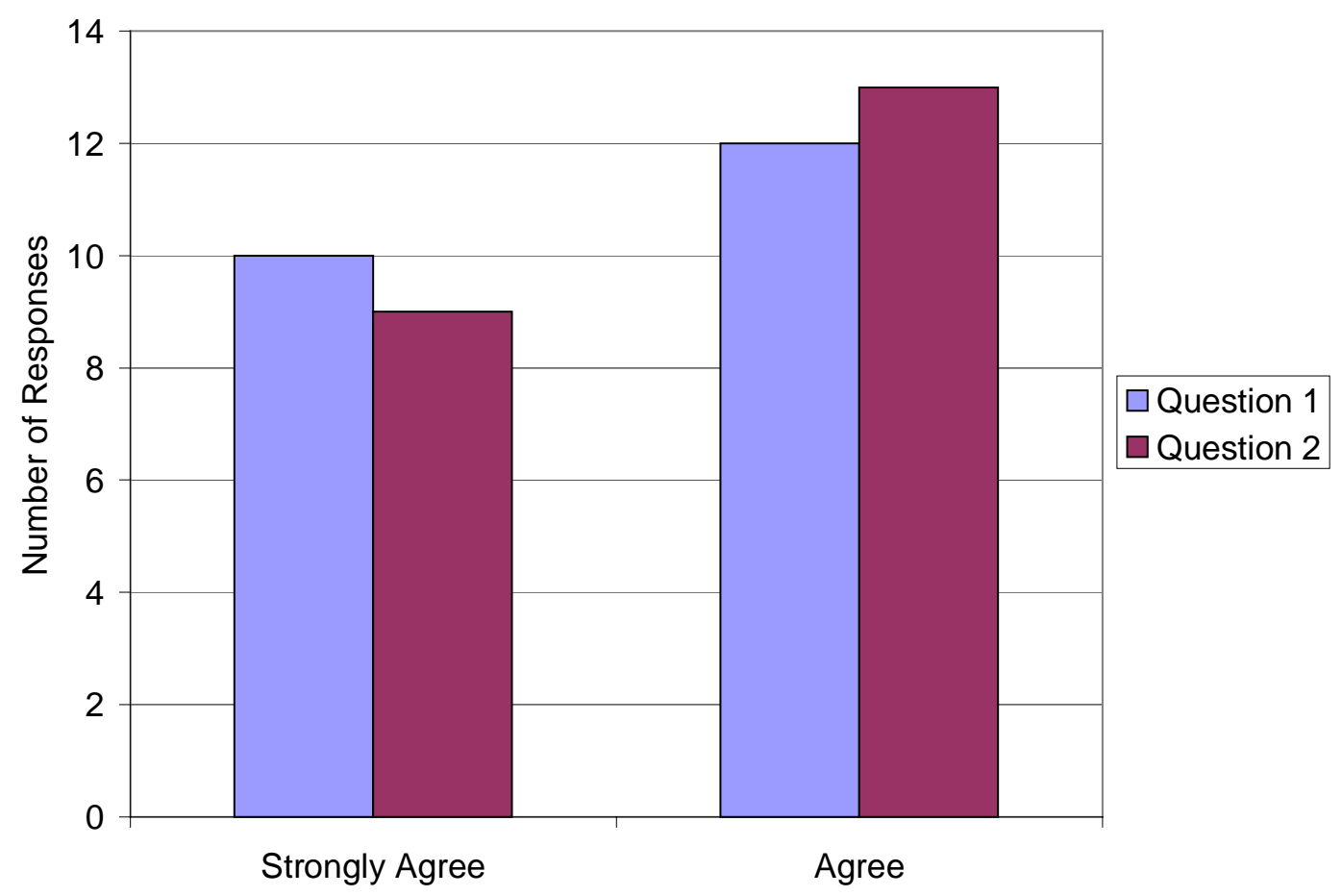

Figure 2. Response Distribution to Survey Questions 1 and 2

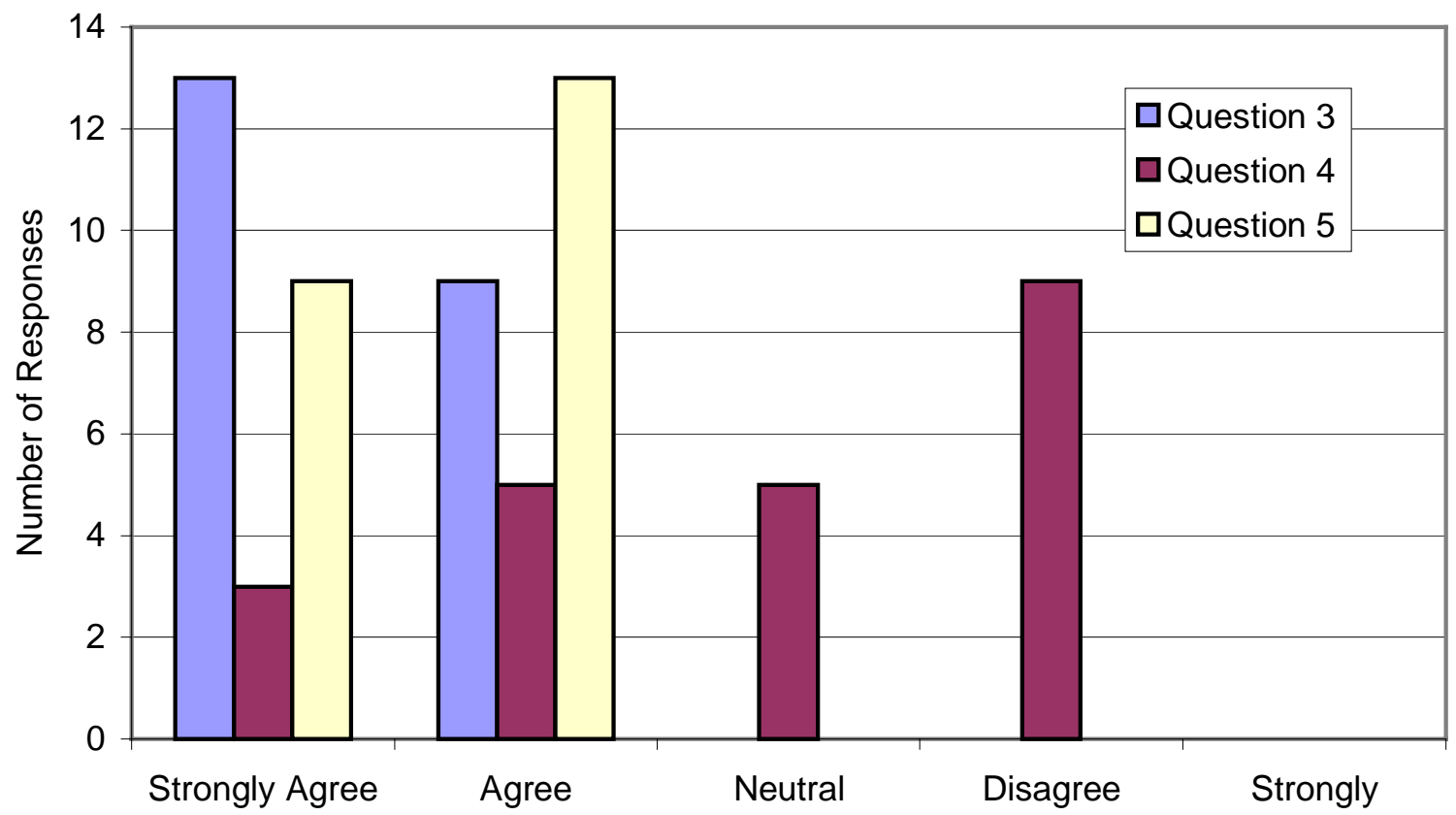

Figure 3. Response Distribution to Survey Questions 3, 4 and 5

Proceedings of the 2001 American Society for Engineering Education Annual Conference \& Exposition Copyright (C) 2001, American Society for Engineering Education 
The first two questions are designed to evaluate the general response of the student body to the new method of instruction. The results, summarized in Table 1, were encouraging and the reaction was very positive to this new approach. Every respondent agreed with the proposed method, as shown in Figure 2. The purpose of the second question was to distinguish between those students who believe that their individual learning differs from their classmates. However, Figure 2 shows that only one student responded differently to Question 2. In this case, the student strongly agreed with Question 1 but simply agreed with Question 2.

Question 3 received the highest total rating with a numerical score of nearly 3.6 and the highest number of Strongly Agree responses with 13, as shown in Figure 3. The remaining 9 students responded with Agree. Two students commented on Question 3 regarding the link between fundamental properties and laboratory testing. One student commented that this new approach would "definitely make some of the lab tests (consolidation and direct shear, in particular) more understandable." A second student noted that he had a "hard time visualizing what was happening" during specific parts of the course and believed this new approach would increase his ability to visualize concepts.

The most unexpected results of this survey are with regard to Question 4 on the reduction of laboratory reports. Table 1 shows that the average response to this question was neutral and Figure 3 shows that many students disagreed with the proposed changes. This is surprising because many students complain during the course that the writing requirements are high for a 1credit hour course. The results of this survey, however, suggest that these former students have quickly realized the value of technical writing. Two students who disagreed with Question 4 commented that writing a report for each and every lab "reinforces the material" and "really makes you understand the concepts." Another student suggested that having multiple reports is the "only way to improve your writing skills." In essence, "practice makes perfect," as one other student stated.

It should be noted that the author has adopted a technical memorandum format for submission of laboratory test results. Each student is required to present an internal memorandum on his or her findings to the instructor. The text is limited to three pages and must be supported by a specific number of tables and/or figures. Although it requires significant time, the author consistently grades all memos and provides feedback, primarily on technical writing style, presentation of data, and ability to properly analyze data. One student commented that "the memo-style report has been very beneficial" to her in professional practice.

Finally, several former students who responded to this survey were simultaneously working for engineering firms and had some field experience prior to taking this course. The comments from those students indicate that the proposed teaching strategy will be successful. One student stated that "involving students in the construction process will be valuable since many students come out of education with no construction knowledge; seeing compaction in the field makes it easier to grasp the concepts in the classroom." According to two more students, being able to link construction practices to the course "dramatically affected my performance" and "makes lab tests more understandable."

Proceedings of the 2001 American Society for Engineering Education Annual Conference \& Exposition Copyright (C) 2001, American Society for Engineering Education 


\section{Summary}

This paper presents the development of a new method for teaching Introductory Geotechnical Engineering to civil and environmental engineering undergraduate students. With this approach, the fundamental properties of soil are discussed in the context of a real field construction project. The lecture course, laboratory course and a current construction project become interconnected to demonstrate how these fundamental properties are determined in the laboratory and how they are useful in the field. The results of a survey conducted among former students suggest that this new method will enhance the learning of students taking this course.

Bibliography

1. Buck Institute for Education URL: http://www.bie.org/pbl/

\section{CHARLES PIERCE}

Charles E. Pierce is an Assistant Professor of Civil and Environmental Engineering at the University of South Carolina at Columbia. He instructs undergraduate students in lecture and laboratory courses on Civil Engineering Materials and Introductory Geotechnical Engineering. Dr. Pierce received a B.S. degree in Civil Engineering from the University of New Hampshire in 1991 and M.S. and Ph.D. degrees in Civil Engineering from Northwestern University in 1993 and 1998, respectively. 